\title{
Modeling and simulation of a 3-p induction motor based on two types of WFA
}

\author{
Ahmed J. Ali ${ }^{1}$, Laith A. Khalaf ${ }^{2}$, Ahmed H. Ahmed ${ }^{3}$ \\ ${ }^{1,3}$ Department of Power Technichal Engineering, Northern Technichal University, Iraq \\ ${ }^{2}$ Private Sector, Iraq
}

\begin{abstract}
Article Info
Article history:

Received Jan 28, 2020

Revised Aug 8, 2020

Accepted Sep 29, 2020

\section{Keywords:}

Cage rotor

Induction motor

Matlab m.file

Steady state response

Winding function approach

ABSTRACT

This paper has been proposed to simulate the transient model of 3- $\Phi$ cage rotor induction motor based on winding function approach (WFA). According to this method the motor is assumed to be consist of an electrical circuits on both stator and rotor. The magneto motive forces (MMF) that have been generated by these circuits play a role for coupling them together. Then mutual and self-inductances will be easily computed using WFA. Two types of WFA have been used to build and simulate the model of the induction motor. In the one part type, it's assumed that the coupling MMF between stator and rotor have a non-sinusoidal shapes according to the actual windings distribution over the motor slots. While in second part type the generated MMF in are assumed to have sinusoidal waveform. The suggested models may be used to simulate the dynamic as well as steady state performance of a faulty and non-faulty motor. A simulation of the suggested models that consists of m-rotor bars and $n$-stator phases multiple coupled circuit-based has been performed using matlab m.file and the results of the motor current have been proved in its nonlinear way by using WFA.
\end{abstract}

This is an open access article under the CC BY-SA license.

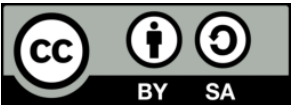

\section{Corresponding Author:}

Ahmed. J. Ali

Department of Power Technichal Engineering

Northern Technichal University, Iraq

Email: ahmedem71@gmail.com

\section{INTRODUCTION}

Due to their robustness, reliability and low requirement for maintenance, three phase induction motors have a many application in industrial processes. Different methods had been used to compute the self and mutual inductances of electric machines. The winding function approach (WFA) had been extensively used to calculate these parameters. The principle of this approach is depending on solving the differential equations that explain the electromagnetic coupling between stator and rotor of the induction motor [1-3]. Calculation of coupled inductances are based on the basic laws of electrical circuit. Firstly, WFA had been applied to compute the inductances of healthy induction motors, then the formulas of this method had been modified to be suitable n-phase conventional induction motors. In the last decades of previous century it had been applied for analysis of linear induction motor [2, 4, 5]. Classical methods that had been used to simulate the electric machines have a limitation to add the effect of winding connection. Generally it assume that both stator and rotor are consists of three phases only and ignore the effect of winding distribution. This drawback had been removed by introducing the WFA where all types of winding can be introduced easily. Also the effects of materials types and saturation can be taken into consideration [6-9]. Then the WFA had been modified in order represents the actual distributions of magnetic flux which gives the correct simulation of electric machine parameters. However, obtaining lower harmonics and simple manufacturing process is a challenge in 
the design and optimization of analyst [10,11]. Due to ability of WFA to simulate any type of winding distribution or a variable air-gap width around rotor, it has been effectively used for modeling and simulation of any type of abnormality of electrical machine operation. Fay model. The ability of WFA makes it more suitable to simulate the inter turn sort circuit between two windings or with other phases in addition to simulate the broken bars of electric machines. Finally it has been successfully for simulation the static, dynamic and mixed rotor eccentricity [10, 12]. Multiple coupled circuit is assumed that the stator of the induction motor consists of n-circuits while the rotor bars of m-circuits. These electrical circuits are mutually coupling and used to determine the inductances of the motor using simple mathematical formulas. WFA give an appropriate way to simulate all machine parameters, stator winding turns, rotor bar and air-gap eccentricities. According to principle of this theory, the mutual and self-inductances between stator winding and rotor bars (windings) stator-rotor circuits can be considered. The relation between these winding is time varying because it depends of the rotor position with respect each other and with stator winding. The leakage inductance of both stator winding and rotor bars are considered as constants and can be computed using special design formulas. In current work two procedure of WFA have been considered. The slot effect is not included in the first type where the coupling mmfs have a sinusoidal shape. While in second approach a real winding distribution in the slots is assumed and mmfs have a non-sinusoidal waveform. A complete model of 3- $\Phi$ cage induction motor which has an m-stator electrical circuits and n-rotor bars is implemented using matlab software [13]. An epic strategy to display electrical machines dependent on WFA is proposed. In traditional WFA, it is accepted that transition lines in air-gap are in outspread heading. The primary downside of this supposition that is incorrectness of the reproduction results. In this technique WFA is improved by limited component strategy in which the definite permeance work is determined by finite element method. This new methodology has a decent exactness adjacent to of low estimation preparing time. In this approach the simulation results are presented and show the performance of the proposed method and these results are compared to experimental results [14-16].

\section{CONSTRUCTION OF THREE PHASE INDUCTION MOTOR MODEL USING WFA}

As stated previously the model of $3-\Phi$ induction motor using a winding function theory has been constructed. It's considers that the model of stator and rotor to be formulated of several electric circuits which are coupled together. Also it's assumed the currents flow through these circuits as an independent variable. The analysis is based on the following assumptions:

- Non-sinusoidal distributed of MMF on the windings of stator where the actual distribution of windings over the stator slots have been taken into consideration.

- Infinity iron permeability $(\mu$ iron $=\infty)$ to introduce the correct behavior of actual motor.

- Uniform air gap and neglected inter-bar currents have been assumed, where each adjacent bar form a separate circuit.

- The rotor bars and the motor windings have been suggested to have a symmetric distribution.

- The effect of saturation at starting and heavy loading are neglected.

- Non-sinusoidal distributed of inductance due to slots effect also has been introduced.

\subsection{Modeling of voltage equations}

The stator of the induction motor model used in current work have a 3- $\Phi$ windings, therefore a three voltage equations are needed to simulate the stator part. The rotor part contains an equally spaced and symmetrical number of circuits formed by two bars that are connected together using the end rings segments as shown in Figure 1 [17].

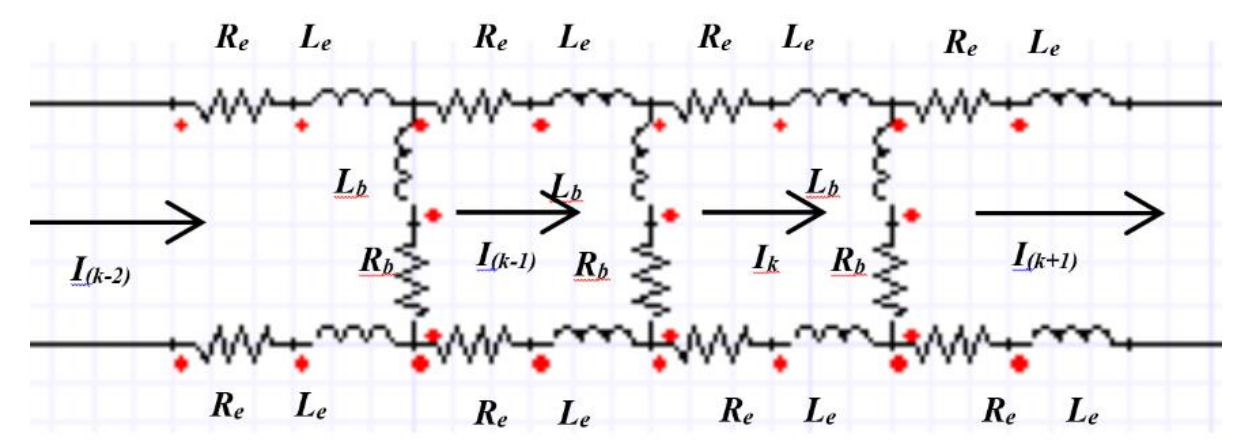

Figure 1. Rotor loops current distribution 
where Figure 1 display the currents distribution of the rotor loops. Both loop shares two rotor bars with the two national rings and two end ring sections with the two end-ring loops. Not the higher shape codes are explained later and according to previous assumptions the complete model of the cage rotor induction motor can be represented by:

$$
\begin{aligned}
& {[V s]=[R s][I s]+d[\varphi s] / d t} \\
& {[0]=[R r][I r]+d[\varphi r] / d t} \\
& {[\varphi s]=[L s][I s]+[L s r][I r]} \\
& {[\varphi r]=[L r][I r]+[L r s][I s]}
\end{aligned}
$$

where, Vs is the vector of the stator voltages, Is is the vector of the stator currents, Ir is the vector of the rotor loops currents, $\mathrm{Rs}$ is the matrix of the stator windings resistances, $\mathrm{Rr}$ is the matrix of the rotor resistances, Ls is the matrix of the stator windings inductances, $\mathrm{Lr}$ is the matrix of the rotor inductances, Lsr and Lrs are the matrix of the mutual inductances between stator and rotor respectively $\varphi s$ and $\varphi r$ are the stator and rotor windings linkage flux respectively $[12,18,19]$.

From (1) and (3), the voltage equations of the stator per phase may be written as:

$$
\begin{aligned}
& \mathrm{V}_{\mathrm{a}}=\mathrm{R}_{\mathrm{s}} \mathrm{I}_{\mathrm{a}}+\left(\mathrm{L}_{\mathrm{a}}+\mathrm{L}_{1 \mathrm{~s}}\right) \frac{d i a}{d t}+\mathrm{L}_{\mathrm{ab}} \frac{d i b}{d t}+\mathrm{L}_{\mathrm{ac}} \frac{d i c}{d t} \\
& \mathrm{~V}_{\mathrm{b}=} \mathrm{R}_{\mathrm{s}} \mathrm{I}_{\mathrm{b}}+\left(\mathrm{L}_{\mathrm{b}}+\mathrm{L}_{1 \mathrm{~s}}\right) \frac{d i b}{d t}+\mathrm{L}_{\mathrm{ba}} \frac{d i a}{d t}+\mathrm{L}_{\mathrm{bc}} \frac{d i c}{d t} \\
& \mathrm{~V}_{\mathrm{c}=} \mathrm{R}_{\mathrm{s}} \mathrm{I}_{\mathrm{c}}+\left(\mathrm{L}_{\mathrm{c}}+\mathrm{L}_{1 \mathrm{~s}}\right) \frac{d i c}{d t}+\mathrm{L}_{\mathrm{ca}} \frac{d i a}{d t}+\mathrm{L}_{\mathrm{cb}} \frac{d i b}{d t}
\end{aligned}
$$

where $V_{a}, V_{b}$ and $V_{c}$ are the per phase stator voltages ia, ib and ic are the per phase stator currents $L_{a}, L_{b}$ and $\mathrm{L}_{c}$ are the per phase stator self-inductances, $\mathrm{L}_{a b}, \mathrm{~L}_{b c}$ and $\mathrm{L}_{c a}$ are the per phase stator mutual inductances $\mathrm{L}_{\mathrm{ls}}$ is the leakage inductance of the stator per phase. These equations are rewritten in suitable way to suit the basic m.file. For example refer to phase "a" the solve one phase current ia ( $t$ ) rewritten of equation in the following from:

$$
\frac{d i a}{d t}=\frac{1}{\mathrm{~L}_{\mathrm{a}}}\left(\left(\mathrm{v}_{\mathrm{a}-} \mathrm{R}_{\mathrm{s}} * i a\right)-\frac{d}{d t}\left(\mathrm{~L}_{\mathrm{ab}} i b+\mathrm{L}_{\mathrm{ac}} i c+\mathrm{L}_{a r} i r\right)\right)
$$

where, $\mathrm{L}_{\mathrm{ab}} \mathrm{L}_{\mathrm{ac}}, \mathrm{L}_{\mathrm{ar}}$ are inductances and their value can be computed based on the position of rotor. Similarly the above equations can be arranged for the other two phases (dib/dt and dic/dt) currents and two damper windings currents. The complete $\mathrm{m}$. file for three phase dynamic model of induction machine. The rotor loops currents (ir1, ir2,..., irn), (Lar1, Lar2,.., Larn) are mutual inductances of stator phase A to rotor loops, (Lbr1, Lbr2,.., Lbrn) are mutual inductances of stator phase B to rotor loops, and (Lcr1, Lcr2,.., Lcrn) are mutual inductances of stator phase $\mathrm{C}$ to rotor loops. All rotor circuits are mutually coupled with each other and with stator phase's windings. Based on 2 and 4 and with depend on Figure 1, the rotor loop voltage equation $\mathrm{k}$ may be given as:

$$
\begin{aligned}
& 0=2\left(\mathrm{R}_{\mathrm{b}}\right) \mathrm{I}_{\mathrm{rk}}-\mathrm{R}_{\mathrm{b}}\left(\mathrm{I}_{\mathrm{r}(\mathrm{k}-1)}+\mathrm{I}_{\mathrm{r}(\mathrm{k}+1)}\right)+2\left(\mathrm{~L}_{\mathrm{b}}+\mathrm{L}_{\mathrm{e}}\right) \mathrm{dI}_{\mathrm{rk}} / \mathrm{d}_{\mathrm{t}}-\mathrm{L}_{\mathrm{b}}\left(\mathrm{dI}_{\mathrm{r}(\mathrm{k}-1)} / \mathrm{d}_{\mathrm{t}}+\mathrm{dI}_{\mathrm{r}(\mathrm{k}+1)} / \mathrm{d}_{\mathrm{t}}\right)+ \\
& \left(\mathrm{L}_{\mathrm{k} 1} \mathrm{dI}_{\mathrm{r} 1} / \mathrm{d}_{\mathrm{t}}+\mathrm{L}_{\mathrm{k} 2} \mathrm{dI}_{\mathrm{r} 2} / \mathrm{d}_{\mathrm{t}}+\cdots+\mathrm{L}_{\mathrm{kk}} \mathrm{dI}_{\mathrm{rk}} / \mathrm{d}_{\mathrm{t}}+\cdots+\mathrm{L}_{\mathrm{kn}} \mathrm{dI}_{\mathrm{rn}} / \mathrm{d}_{\mathrm{t}}\right)-\mathrm{d} / \mathrm{d}_{\mathrm{t}}\left(\mathrm{L}_{\mathrm{ak}} \mathrm{I}_{\mathrm{a}}+\mathrm{L}_{\mathrm{bk}} \mathrm{I}_{\mathrm{b}}+\mathrm{L}_{\mathrm{ck}} \mathrm{I}_{\mathrm{c}}(9)\right.
\end{aligned}
$$

where, $\mathrm{Re}, \mathrm{rb}, \mathrm{Lb}$,Le, are the resistance and inductance of each rotor bar. Lkk is the self inductance of each rotor loop $(\mathrm{Lk} 1, \mathrm{Lk} 2, \ldots, \mathrm{Lk}(\mathrm{k}-1), \mathrm{Lk}(\mathrm{k}+1) \ldots, \mathrm{Lkn})$ are the mutual inductances loop $\mathrm{k}$ to the other rotor loops (Lak, Lbk, and Lck) are the stator mutual inductances with rotor loop k.

\subsection{Equation of electromagnetic torque}

The equation of the electromagnetic torque can be determined based on the energy conversion theory, the electromagnetic torque equation produced by a 3-phase induction motor can be computed using the following equation [12]:

$$
\mathrm{T}_{\mathrm{e}}=\left[i_{s}\right]^{T}\left[\frac{d L_{S r}}{d L_{\theta r}}\right]\left[i_{\mathrm{r}}\right]
$$

where, $\theta \mathrm{r}$ is the angular position of rotor, Te is the developed torque produced by the motor. 


\subsection{Electromechanical equation}

The mechanical equation of rotor may be written as $[12,18]$ :

$$
\begin{aligned}
& \mathrm{T}_{\mathrm{e}}=\mathrm{j} d \mathrm{dw}_{\mathrm{r}} / \mathrm{d}_{\mathrm{t}}+B \mathrm{w}_{\mathrm{r}}+\mathrm{TL} \\
& w_{r}=\frac{1}{P} \frac{d \theta \mathrm{r}}{d t}
\end{aligned}
$$

where,

$\mathrm{J} \quad$ is moment of inertia of rotor,

$\mathrm{W}_{\mathrm{r}}$ is rotor angular speed,

$\mathrm{B}$ is the friction coefficient.

TL is the load torque,

$\mathrm{Or}$ is the angular position of the rotor.

\section{NON-SINUSOIDAL SHAPES SELF AND MUTUAL INDUCTANCE FORMULA USING WFA}

The important key of WFA of the induction motor is to compute the values of inductances equations accurately, in $[2,3]$ the winding function method had been applied in order calculate the inductances of the motor in terms angular position of rotor $\theta \mathrm{r}$. WFA is an analytical method used to calculate the self and mutual inductances based on the distribution of MMF in the air-gap region due to a follow a current of "1" A value pass through the winding under consideration. From the principles of WFA, it's evident that it's required to calculate all the inductances of the machine using the inductance matrices. These inductances are normally determined using WFA. The general formula that will be used to calculate the motor inductances (self and mutual) is defined by (11). Using winding function approach, the mutual inductance between two coupled electric circuits (stator phases or rotor bars) for any electrical machine may be determined using the following equation [20-24]:

$$
\mathrm{L}_{\mathrm{ij} \theta)}=\mu o I r / g \int_{0}^{2 \pi} \lambda_{i}(\theta r, \vartheta) \lambda_{j}(\theta r, \vartheta) d_{\vartheta}
$$

where: $\mu O$ is the permeability of air and $=4 \pi .10-7 \mathrm{H}, g$ is the width of the air gap, $\theta$ is the angular position of the rotor, $r$ is the average radius of the air gap, $l$ is the effect length of the motor stack, $\vartheta$ is a certain point along the air gap, $\lambda(\theta, \vartheta)$ is called the winding function and represents the distribution of the magneto motive force along the air gap when a current of '1' A flow in the winding. In current paper a three phase induction motor, 36 stator slots and symmetrical concentrate winding. While the cage rotor of the motor compromise a 28-equally spaced bars. The geometric construction of the motor has been taken into consideration, where the slots effect on the stator winding is considered. The self any two stator phases $\mathrm{L}_{\mathrm{aa}}$, $\mathrm{L}_{\mathrm{bb}}, \mathrm{L}_{\mathrm{cc}}$ have been calculated based on WFM as given in (14). Where the motor inductances formulas can be written as [25-27]:

$$
\begin{aligned}
& \mathrm{L}_{\mathrm{a}}=\mathrm{L}_{\mathrm{b}}=\mathrm{L}_{\mathrm{c}}=\left(\mathrm{N}_{\mathrm{S}} / 2 \mathrm{p}\right)^{2}\left(\pi \mu_{0} \mathrm{~L}_{\mathrm{r}} / \mathrm{g}\right)=\mathrm{L}_{\mathrm{ms}} \\
& \mathrm{L}_{\mathrm{ab}}=\mathrm{L}_{\mathrm{bc}}=\left(\mathrm{N}_{\mathrm{S}} / 2 \mathrm{p}\right)^{2}\left(\pi \mu_{0} \mathrm{~L}_{\mathrm{r}} / 2 \mathrm{~g}\right)=-\mathrm{L}_{\mathrm{ms}} / 2 \\
& \mathrm{~L}_{\mathrm{kk}}=\left(\frac{\pi_{0} \mathrm{~L}_{\mathrm{r}}}{\mathrm{g}}\right)\left(1-\frac{\alpha_{\mathrm{r}}}{2 \pi}\right) \alpha_{\mathrm{r}} \\
& \mathrm{L}_{\mathrm{k} 1}=\mathrm{L}_{\mathrm{k} 2}=\cdots=\mathrm{L}_{\mathrm{kn}}=\mathrm{L}_{\mathrm{ki}}\left(\frac{\pi_{0} \mathrm{~L}_{\mathrm{r}}}{\mathrm{g}}\right)\left(\alpha_{\mathrm{r}}\right)^{2} / 2 \pi \\
& \mathrm{L}_{\mathrm{ak}}=\mathrm{L}_{\mathrm{m}} \cos \left(\mathrm{p}\left(\theta_{\mathrm{r}}+(\mathrm{k}-1) \alpha_{\mathrm{r}}+\delta\right)\right) \\
& \mathrm{L}_{\mathrm{bk}}=\mathrm{L}_{\mathrm{m}} \cos \left(\mathrm{p}\left(\theta_{\mathrm{r}}+(\mathrm{k}-1) \alpha_{\mathrm{r}}+\delta\right)-2 \pi / 3\right) \\
& \mathrm{L}_{\mathrm{ck}}=\mathrm{L}_{\mathrm{m}} \cos \left(\mathrm{p}\left(\theta_{\mathrm{r}}+(\mathrm{k}-1) \alpha_{\mathrm{r}}+\delta\right)+2 \pi / 3\right)
\end{aligned}
$$

where: Ns is the number of stator turns per phase, $\mathrm{p}$ is the number of pole pairs, $\alpha \mathrm{r}$ is the angle between two neighboring bars $L_{m}=\left(4 / \pi N_{s}\right) L_{m s} \sin (\mathrm{p} \delta)$, where $\delta=\alpha_{r} / 2$. 


\section{SIMULATION RESULTS}

The flux equations have been used to simulate the proposed model. The simulated steps that have been used to solve the differential equations of the induction motor are explained in the algorithm shown in Figure 2. The integration of flux linkage derivatives with respect to time are calculated to obtain flux linkages, as follows:

$$
\begin{aligned}
& \frac{\mathrm{d} \varphi}{\mathrm{dt}}=\mathrm{v}_{\text {source }}-\mathrm{RI} \\
& \varphi=\int\left(\mathrm{v}_{\text {source }}-\mathrm{RI}\right)=\mathrm{L}_{\text {self }} \mathrm{I}_{\text {self }}+\Sigma \mathrm{L}_{\text {mutual }} \mathrm{I}_{\mathrm{i}}
\end{aligned}
$$

Matlab m-file has been used to simulate the dynamic equations of a 3- $\Phi$ cage rotor induction motor. The proposed mathematical model has been used to simulate the time response performance of a $4 \mathrm{~kW}$ induction motor with the parameters given in Table 1.

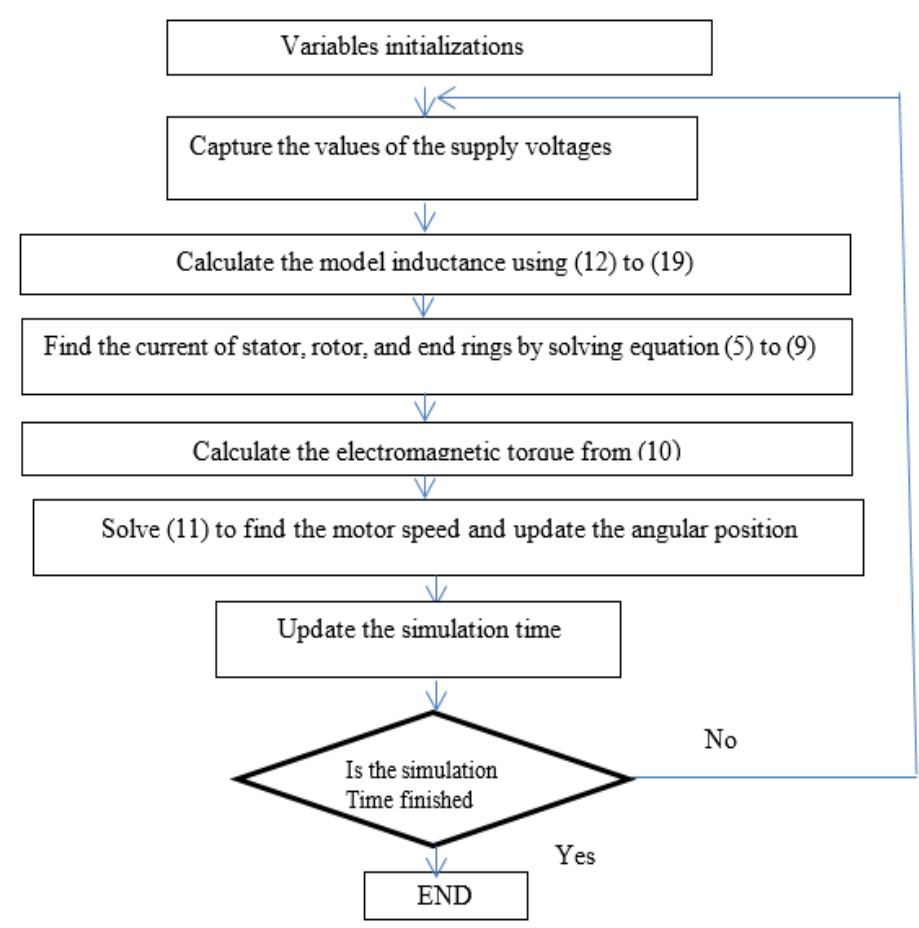

Figure 2. Algorithm of simulation

Table 1. Parameters of induction motor model

\begin{tabular}{ll}
\hline Input Supply Phase Voltage & $220 \mathrm{Volt}$ \\
Input Supply Frequency & $50 \mathrm{~Hz}$ \\
STATOR PARAMETERS & \\
Effective Number of Stator winding turns: $\mathrm{N}_{\mathrm{s}}$ & $156 \mathrm{turn}, 36$ stator slots \\
Stator windings Ohmic resistance: $\mathrm{R}_{\mathrm{s}}$ & $1.5 \mathrm{ohm}$ \\
Stator windings Leakage inductance: $\mathrm{L}_{1 \mathrm{~S}}$ & $7 \mathrm{Mh}$ \\
Number of pole pairs: $\mathrm{p}$ & 4 \\
ROTOR PARAMETERS & \\
Number of rotor bars: $\mathrm{n}$ & 28 \\
Rotor bar resistance: $\mathrm{R}_{\mathrm{b}}$ & $96.940036 \mu \Omega$ \\
End ring segment resistance: $\mathrm{R}_{\mathrm{e}}$ & $5 \mu \Omega$ \\
Rotor bar self inductance: $\mathrm{L}_{\mathrm{b}}$ & $0.28 \mu \mathrm{H}$ \\
End ring segment self inductance: $\mathrm{L}_{\mathrm{e}}$ & $0.036 \mu \mathrm{H}$ \\
AIR GAP PARAMETERS & \\
Air gap average radius: $\mathrm{r}$ & $70 \mathrm{~mm}$ \\
Air gap length: $\mathrm{g}$ & $0.28 \mathrm{~mm}$ \\
Rotor effective length: $\mathrm{L}$ & $120 \mathrm{~mm}$ \\
MECHANICAL PARAMETERS & \\
Inertia: J & $0.007 \mathrm{~N} . \mathrm{sec}^{2}$ \\
Friction coefficient: F & $0.001 \mathrm{~N} . \mathrm{sec}^{2}$ \\
\hline
\end{tabular}


According to the two suggested approaches, the model of motor has been simulated under operation conditions by applying a load torque of $\mathrm{TL}=3.5 \mathrm{Nm}$ on the shaft, starting time from zero, applying of 220 volt and $50 \mathrm{~Hz}$. The time response of the stator current are shown in Figure 3 at Non-sinusoidal shapes self and mutual inductance. Also the dynamic characteristics (Mutual inductance, rotor speed and developed torque) are shown in Figures 4-6. The WFA principle is based on the coupling between stator and rotor as shown Figure 4. Then for the second approach, the model has been simulated under the same operating conditions mentioned for first approach. It's clear from the simulation results of stator and rotor currents are shown in Figure 7 and Figure 8 that waveform have a smooth shape compare with Figure 3. This unifomlly and reular current is due to sinusoidal assumption of mutual inductance that couple between the stator and rotor.

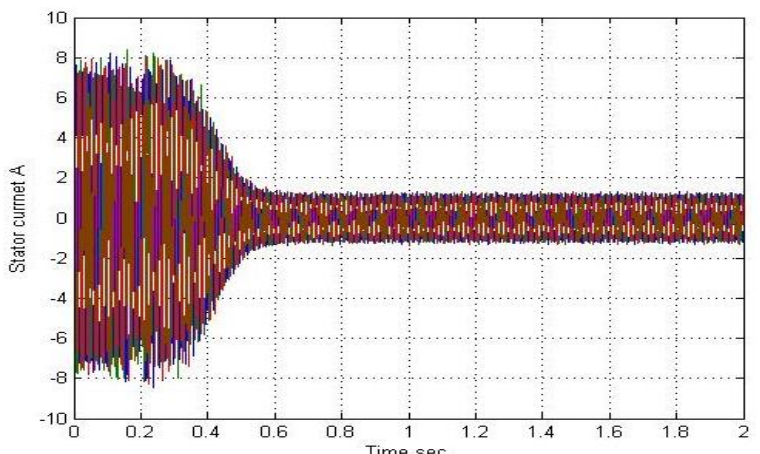

(a)

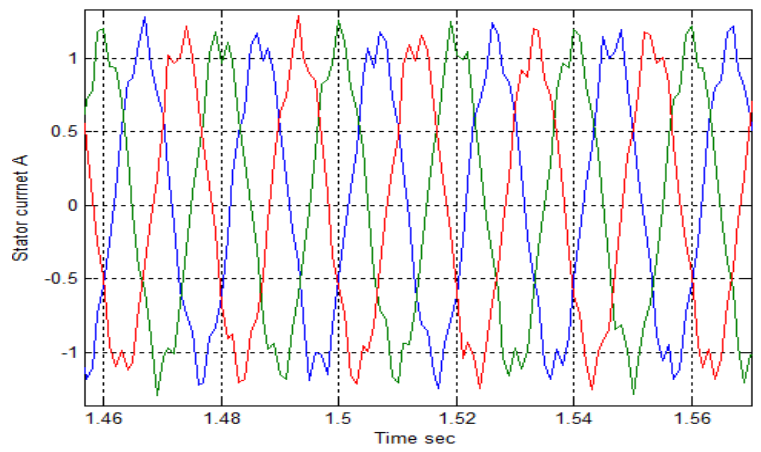

(b)

Figure 3. The time response of the stator current, ( $\mathrm{a}$ and $\mathrm{b}$ ) stator current at non-sinusoidal shapes self and mutual inductance using WFA

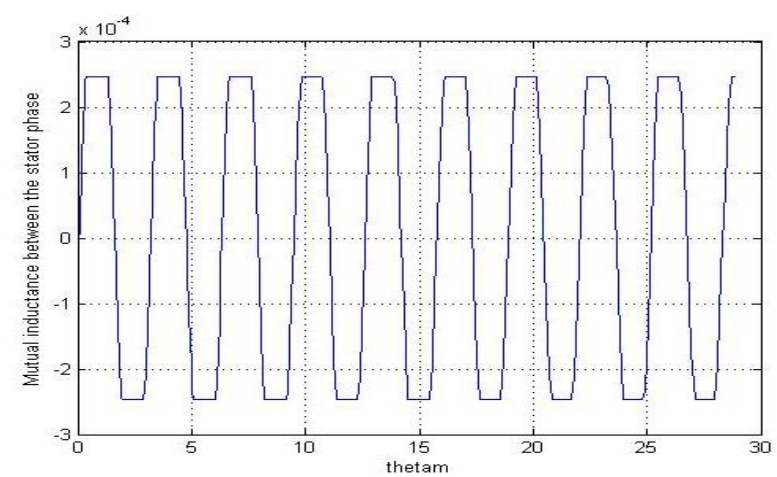

Figure 4. Mutual inductance between stator and rotor

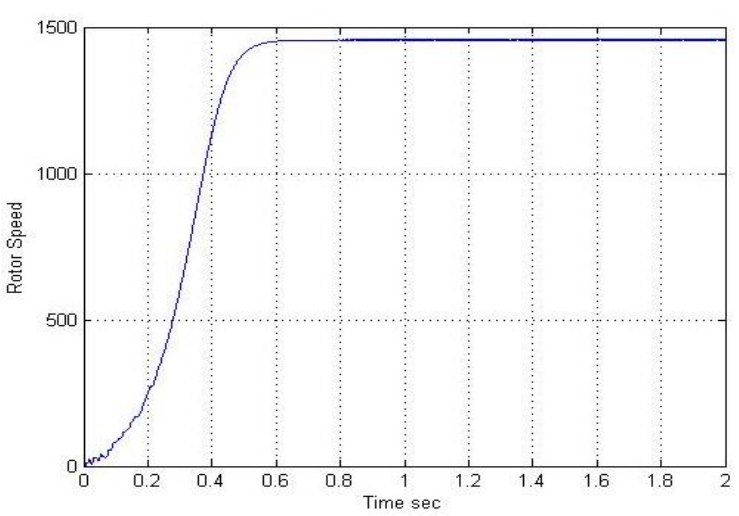

Figure 5. Rotor speed (rpm)

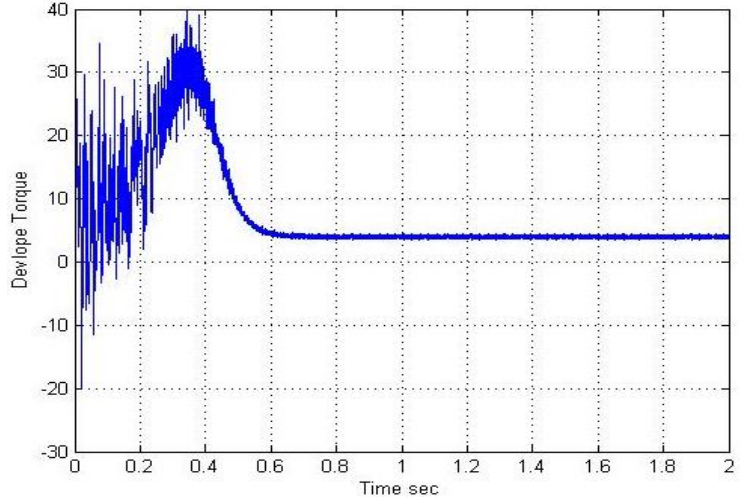

Figure 6. Developed torque (N.m) 


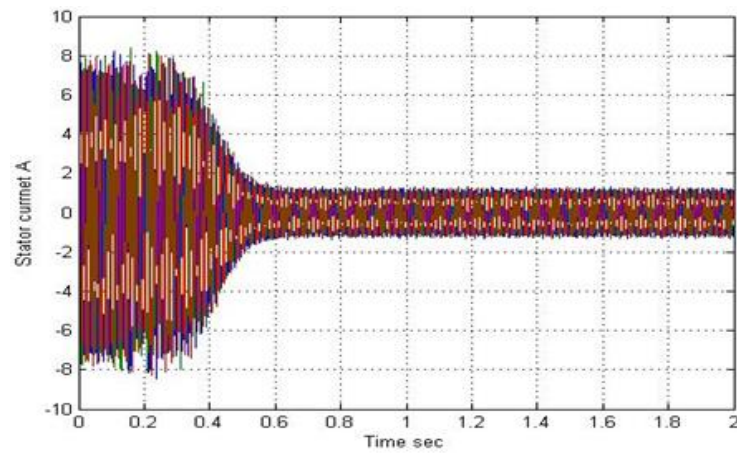

(a)

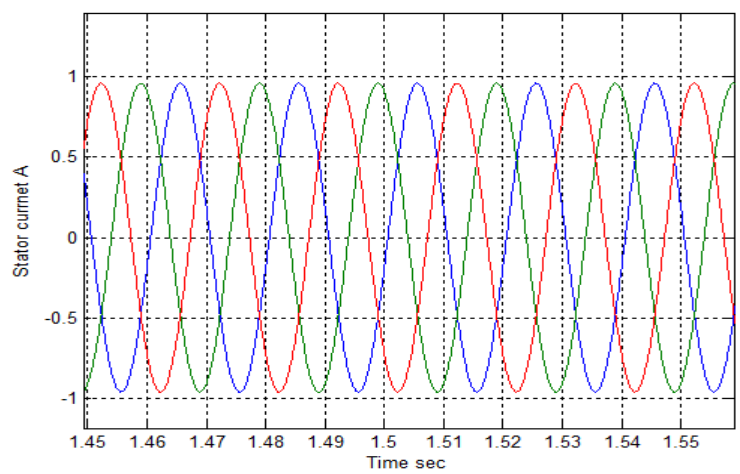

(b)

Figure 7. The simulation results of stator, ( $a$ and $b$ ) stator currents due to sinusoidal shapes self and mutual inductance using WFA

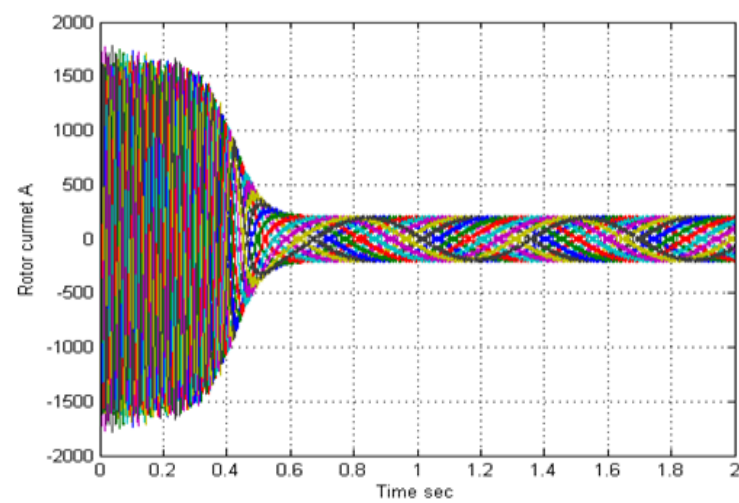

(a)

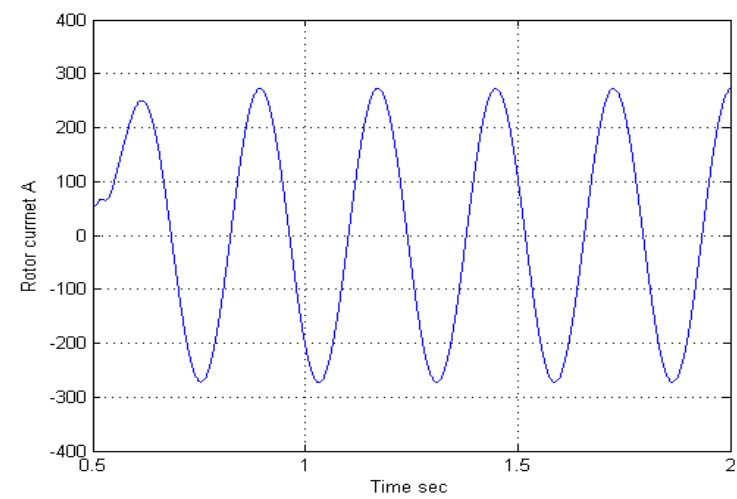

(b)

Figure 8. The simulation results of rotor, ( $\mathrm{a}$ and $\mathrm{b}$ ) rotor currents due to sinusoidal shapes self and mutual inductance using WFA

\section{CONCLUSION}

Two types of winding function approaches have been modeled and simulated in this paper. It's obvious from the results that the first model has results different slightly from the second approach. For the stator, rotor currents and torque they have a non-smooth and ripple shapes compared with the results obtained from the second model. This non-linearity is due to the actual winding distribution on the motor slots. The stator MMF have a non-sinusoidal waveform due to slots effect which make this model more suitable to simulate the faulty motor compared with first type.

\section{REFERENCES}

[1] J. Carrera, R. Franceschi, G. Gonzalez, "Induction Motor Fault Modeling Based on the Winding Function," ESTEC Conference Proceedings 6th Engineering, Science and Technology Conference, vol. 2018, 2017, pp. 758-767.

[2] N. L. Shmitz and D. W. Novotny, "Introductory Electromechanics," NewYork: Roland, 1965.

[3] M. Ghods, Z. Nasiri-Gheidari, F. Tootoonchian and A. Oraee, "Performance Evaluation of Permanent Magnet Vemier Generator Based on Modified Winding Function Method," Electrical Engineering (ICEE), Iranian Conference on, Mashhad, 2018, pp. 1107-1112.

[4] Basil M. Saied, Ahmed. H. Ahmed, "Modeling and Simulation of Salient Pole Synchronous Machine with Comparison between Actual and d-q Models," Second Scientific Engineering Conference, Mosul, vol. 2, pp. 41-56, 2013.

[5] R. Krall, J. Krenn and A. Schmid, "Fractional slot winding versus distributed winding using winding function method," 2014 International Conference on Optimization of Electrical and Electronic Equipment (OPTIM), Bran, 2014, pp. 437-444.

[6] Ah-Jaco A., "Modélisation des moteurs asynchrones triphasés en régime Transitoire avec saturation et harmoniques d'espace: Application au diagnostic," thèse de doctorat de l'université de Lyon juillet, 1997.

[7] J. C. Moreria and T. A. Lipo, "Modeling of saturated AC machines including air gap flux harmonic components," in IEEE Transactions on Industry Applications, vol. 28, no. 2, pp. 343-349, 1992. 
[8] K. C. Deekshit Kompella, M. Venu Gopala Rao, R. Srinivasa Rao, "Baring Fault Diagnoses in 3 phase Induction Machine Using Current Spectral Subtraction With Different Wavelet Transform Techniques," Journal of Electrical System, vol. 13, no. 1, pp. 143-159, 2017

[9] A. Doulatshah and P. Naderi, "Eccentricity fault detection of a salient-pole synchronous machine using modified winding function approaches and finite element method," 2016 th Power Electronics and Drive Systems Technologies Conference (PEDSTC), Tehran, 2016, pp. 29-34.

[10] H. A. Toliyat, M. M. Rahimian, and T. A Lipo, "Transient analysis of cage induction machines under internal faults using winding function," 3rd Int. Conf. Electrical Rotating Machines-ELROMA, 2006.

[11] R. Alipour-Sarabi, Z. Nasiri-Gheidari, F. Tootoonchian and H. Oraee, "Improved Winding Proposal for Wound Rotor Resolver Using Genetic Algorithm and Winding Function Approach," in IEEE Transactions on Industrial Electronics, vol. 66, no. 2, pp. 1325-1334, 2019.

[12] H. A. Toliyat and T. A Lipo, "Transiant analysis of cage induction machines under stator, rotor bar and end ring faults," in IEEE Transactions on Energy Conversion, vol. 10, no. 2, pp. 241-247, 1995.

[13] S. M. Raziee, O. Misir and B. Ponick, "Winding Function Approach for Winding Analysis," in IEEE Transactions on Magnetics, vol. 53, no. 10, pp. 1-9, 2017.

[14] M. Nourmohammadpour, M. Khalilzadeh and K. Abbaszadeh, "Accurate modeling of switched reluctance motor by using improved winding function method," 2014 22nd Iranian Conference on Electrical Engineering (ICEE), Tehran, 2014, pp. 793-797.

[15] F. Boubakar, A. Aissa, K. Abdellah and Z. Abdellim, "A three dimensional finite element method analysis and winding function theory for torque ripple reducing in reluctance machine," 2016 8th International Conference on Modelling, Identification and Control (ICMIC), Algiers, 2016, pp. 418-423.

[16] F. Boubakar, K. Abdellah, A. Mehdi and A. Aissa, "Torque ripple reducing in SRM based on winding function theory and 3D Finite Element Methods," 2015 4th International Conference on Electrical Engineering (ICEE), Boumerdes, 2015, pp. 1-5.

[17] S. Nandi, S. Ahmed, and H. A. Toliyat, "Detection of rotor slot and other eccentricity related harmonics in a three phase induction moto with different rotor cages," in IEEE Transactions on Energy Conversion, vol. 16, no. 3, pp. 253-260, 2001.

[18] H. A. Toliyat and M. S. Arefeen, "A method for dynamic simulation of air-gap eccentricity in induction machines," in IEEE Transactions on Industry Applications, vol. 32, no. 4, pp. 910-918, 1996.

[19] G. M. Joksimovic, J. Penman, and N. Arthur, "Dynamic simulation of dynamic eccentricity in induction machineswinding function approach," in IEEE Transactions on Energy Conversion, vol. 15, no. 2, pp. 143-148, 2000.

[20] Petar Matić, Aleksandar Rakić, Slobodan N. Vukosavić, "Space Vector Representation of Induction Motor Model in Field Weakening Regime,” Serbian Journal of Electrical Engineering, vol. 9, no. 1, pp. 53-61, 2012.

[21] Toliyat H. A., Lipo T. A., and White J. C., "Analysis of a concentrated winding induction machine for adjustable speed drive application. I. Motor analysis," IEEE Transaction on Energy Conversion, vol. 6, no. 4, pp. 679-684, 1991.

[22] Luo X., Liao Y., Toliyat H.A., El-Antably A. and Lipo T.A., "Multiple coupled circuit modeling of induction machines," IEEE Transaction on Industry apllications, vol. 31, no. 2, pp. 311-318, 1995.

[23] S. Shah, A. Rashid, M. K. L. Bhatti, "Direct Quadrate (D-Q) Modeling of 3-Phase Induction Motor Using MatLab/Simulink," Canadian Journal on Electrical and Electronics Engineering, vol. 3, no. 5, pp. 237-243, 2012.

[24] Ahmed. J. Ali, Ahmed. H. Ahmed and B. M. Saied, "Cogging torque Mitigation for PMSM using stator slots design and Magnets skewing," 2019 2nd International Conference on Electrical, Communication, Computer, Power and Control Engineering (ICECCPCE), Mosul, Iraq, 2019, pp. 240-245.

[25] D. Uma, K. Vijayarekha, "Modeling and Simulation of VSI Fed Induction Motor Drive in Matlab/Simulink," International Journal of Electrical and Computer Engineering (IJECE), vol. 7, no. 2, pp. 584-595, 2017.

[26] M. Zuo and H. Guo, "Integrative simulation and analysis of induction motor and control system," Proceedings of 2011 International Conference on Electronic \& Mechanical Engineering and Information Technology, Harbin, 2011, pp. 2412-2414.

[27] K. E. Amin, R. M. Hamouda, A. D. Elkoshairy and M. A. El-Dessouki, "Dynamic Analysis of Electromechanical Oscillations in Cascaded Induction Motors Driving Different Loads," 2019 21 st International Middle East Power Systems Conference (MEPCON), Cairo, Egypt, 2019, pp. 473-477.

\section{BIOGRAPHIES OF AUTHORS}

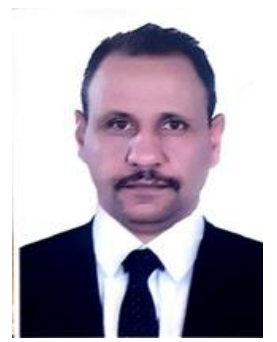

Ahmed J. Ali is a lecture at department of Power Engineering Technology/Engineering Technical College/Mosul. He has get B.Sc.and M.Sc. degree from Al-Thechnologia University/ Baghdad In 1995 and 2004 respectively in Electrical Engineering. He has finish his Ph.D. degree in Electrical Machines from university of Mosul in 2013. His filed of work concentrate on Adaptive and Intelligent control Systems, Electric machines Design and Drives. Now he is a lecturer at Power Engineering Technology Department/Technical Engineering College/Mosul. 


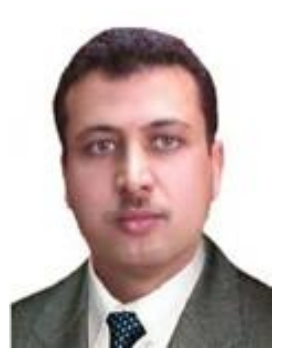

Laith A. Khalaf is a lecture at department of Power Engineering Techniques/Engineering Technical College/Mosul/Northern Technical University. He has get B.Sc. and M.Sc. degree from Al-Thechnologia University/Baghdad In 1995 and 2001 respectively in Electrical Engineering Department Power \& Machines. His filed of work concentrate on Adaptive and Intelligent pwer electronics Electric machines Design and Drives. Now he is a lecturer at Power Engineering Techniques department/Technical Engineering College/Mosul

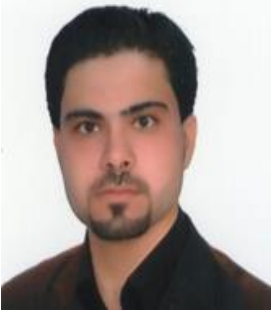

Ahmed Hashim Ahmed is a lecture at department of Computer Engineering Technology/ Engineering Technical College/Mosul. He has get B.Sc. and M.Sc. degree from mosul University/Mosul. In 2006 and 2014 respectively in Electrical Engineering. His filed of work concentrate on Adaptive and Intelligent control Systems, Electric machines Design and Drives. Now he is a lecturer at Computer Engineering Technology Department/Technical Engineering College/Mosul. 